\title{
Employment in Myasthenia Gravis: A Systematic Literature Review and Meta-Analysis
}

\author{
Erika Guastafierro $^{\mathrm{a}}$ Irene Tramacere ${ }^{\mathrm{b}}$ Claudia Toppo $^{\mathrm{a}}$ Matilde Leonardi $^{\mathrm{a}}$ \\ Renato Mantegazza ${ }^{c}$ Silvia Bonanno ${ }^{c}$ Rita Frangiamore ${ }^{c}$ Alberto Raggi ${ }^{a}$ \\ a UOC Neurologia, Salute Pubblica, Disabilità, Fondazione IRCCS Istituto Neurologico Carlo Besta, Milano, Italy;

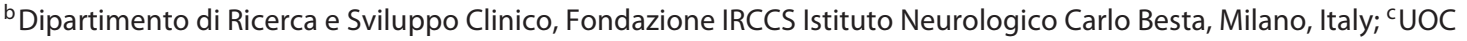 \\ Neurologia 4, Neuroimmunologia e Malattie Neuromuscolari, Fondazione IRCCS Istituto Neurologico Carlo Besta, \\ Milano, Italy
}

\section{Keywords}

Myasthenia gravis · Work · Employment · Systematic review · Meta-analysis

\begin{abstract}
Introduction: Myasthenia gravis (MG) is an autoimmune disease whose period of typical onset is around $20-40$ years (i.e., early onset), thus in the peak of working age, or around 60-80 years (i.e., late onset). However, the information on work-related issues and employment status are sparse and not systematically reported. Therefore, we performed a systematic literature review with meta-analysis to address the employment status of MG patients. Methods: We searched for papers reporting employment status on participants with MG published between January 2000 and May 2019. Information on employment was extracted. Random-effects models were used to produce meta-analytic estimates for the proportion of employed patients. Results: In total, 1,045 records were retrieved, of which 19 fitted the inclusion criteria. In total, 3,600 participants (average age 47.5, range 3560 ) were included in the studies and 1,579 of them were employed. The proportion of employed patients varied from 28 to $82 \%$, with an extreme heterogeneity between studies.
\end{abstract}

Overall, the pooled proportion of workers was 50\% (95\% Cl 41-60\%). Subgroup analyses suggested a possible, although not significant, higher proportion of workers among women, younger participants, those with a higher level of education, shorter MG duration, and less frequently thymectomized, whereas a lower proportion was observed among those with generalized, bulbar, and respiratory symptoms. Conclusions: The results of our meta-analysis show that the percentage of employment is considerably low if we take into account that the mean age of MG patients involved in the included studies was around 48 years, thus in peak of working life. Therefore, it is important to understand what kind of influence MG exerts on work dynamics.

(c) 2020 S. Karger AG, Basel

\section{Introduction}

Myasthenia gravis (MG) is an autoimmune disease caused by autoantibodies to the postsynaptic site of the neuromuscular junction that induces weakness and fatigability of skeletal muscles [1,2]. MG has different forms, and its impact on patients' daily life depends on symptoms' severity and on muscle involvement, which is usu-

\section{KARGER}

(c) 2020 S. Karger AG, Basel

karger@karger.com

www.karger.com/ned
Erika Guastafierro

Neurology, Public Health and Disability Unit

Neurological Institute C. Besta IRCCS Foundation

Via Celoria 11, IT-20123 Milan (Italy)

E-Mail erika.guastafierro@ istituto-besta.it 
ally categorized as ocular, generalized, bulbar, or respiratory $[3,4]$. In recent studies, the prevalence rate of MG varies between 10.66 and 32.89 per 100,000 [5-7]. It is more common among women (about $70 \%$ ), and the period of onset is around 20-40 years old (i.e., early onset), but late onset, which may span also up to 60-80 years old, is frequent as well $[3,8,9]$.

Thus, MG affects persons of working age and causes significant limitations in daily life activities $[10,11]$, including patients' involvement in work duties and therefore employment status [12]. The severity of interference in physical activities induces MG patients to modify the amount of physical work and, for example, to reduce working hours or to limit the kind of work activities to those not involving physical exertion [12]. However, many studies analyzed only the physical symptoms and limitations [13-15], and some psychosocial aspects, such as quality of life (QoL) [10,16,17], largely ignoring workrelated issues. In addition, only few studies focused on the burden of MG in terms of costs, participation, work-related difficulties, sick leave, and job loss. For example, the study by Twork et al. [18] highlighted that $30.8 \%$ of respondents were employed but only $25.8 \%$ of patients worked $>15 \mathrm{~h} /$ week. Conversely, in a study by Frost et al. [19], 82.1\% of the sample was employed but after the diagnosis of MG $41.2 \%$ of patients experienced 9 or more weeks per years of sick leave. Thus, these studies report very different data on the proportion of employed patients and focused on different aspects of working life, and the information on work-related issues are sparse and not systematically reported. Therefore, we performed a systematic literature review with meta-analysis to address the employment status of MG patients.

\section{Methods}

\section{Data Sources and Data Extraction}

We searched SCOPUS looking for records containing the term "Myasthenia" in title, abstract, or keywords published in the period comprised between January 2000 and May 2019, so to get recent data on employment, and written in English. We looked for primary research articles, so excluded editorials, reviews, letter to the editors, conference proceedings, notes and erratum, books, and retracted articles.

We applied SCOPUS filters to exclude papers indexed in those subject areas clearly not dealing with the topic (e.g., arts and humanities, energy, material sciences, veterinary) and that would retrieve papers in which sample of human tissues, rather than patients, are included (e.g., biochemistry, genetics and molecular biology, Pharmacology, Toxicology, and Pharmaceutics). We also applied filters to exclude keywords referred to nonhumans, children, adolescents, or people aged 65 or over, or patients with con- ditions different from MG. Please see online supplementary Materials (see www.karger.com/doi/10.1159/000506310) for the complete search strategy.

At abstract check, we excluded studies that were based on animals and on biological samples (e.g., thymus tissues or blood samples); were not written in English; were reviews, letters to editors, books, editorials, case studies, and studies based on $<10$ participants; included only patients of non-working age (i.e., children and people aged 65 or over). At full-text screening, we selected those manuscript that enabled the identification of the number of employed subjects in each study (i.e., "employed," "unemployed," "type of occupation").

Extracted information included employment status, that is, the fact that a given number of patients were identified as "employed" at the time of enrolment in the study with any kind of contract: this include employees, employers, and freelancers. In addition to these information, we extracted the following variables: gender, age, and symptoms duration in years, education (primary, secondary, high, university), previous thymectomy, prescribed medications at the time of inclusion in the study (pyridostigmine bromide, steroids, and immunomodulators, e.g., azathioprine, cyclosporin, mycophenolate mofetil, and cyclophosphamide), and MG type at the time of inclusion in the study. MG type was defined relying on the MG Foundation of America or on the Besta Neurological Institute rating scale for MG classification systems [20,21], based on data availability.

\section{Data Analysis}

The measure of interest was the proportion of workers among subjects with MG. The confidence intervals were based on the score (Wilson) procedure [22]. All the meta-analytic estimates were derived using random-effects models [23]. The pooled estimates were calculated after Freeman-Tukey Double Arcsine Transformation [24] to stabilize the variances. We assessed the heterogeneity among studies using the $\chi^{2}$ test [25], defining a significant heterogeneity as a $p$ value of $<0.10$, and quantified the inconsistency using the $I^{2}$ statistic [26]. The following subgroup analyses were performed: by sex; age; educational level that was divided into primary and secondary school, high school and university; symptom duration; thymectomy; type of medication that was divided into pyridostigmine, steroids, and immunomodulatory treatments; type of MG-related muscle involvement divided into asymptomatic, ocular, and a single group for generalized, bulbar, and respiratory. We adopted such a division for MG-related muscle involvement because it is not infrequent that studies address one kind of patients (e.g., only with bulbar symptoms) or discern between ocular and the other ones. In each subgroup analysis, the included studies were divided into 2 groups based on the corresponding median value (e.g., in the subgroup analysis by sex, we compared studies with a proportion of women $\geq$ median value calculated on all studies, that is, $59 \%$ versus those with a proportion of women $<59 \%$ ).

\section{Results}

The search yielded 1,045 results. Of these, 19 articles fitted the inclusion criteria related to the employment status and thus were considered for the analysis (Fig. 1) [17- 
Fig. 1. Flow chart of papers' selection.

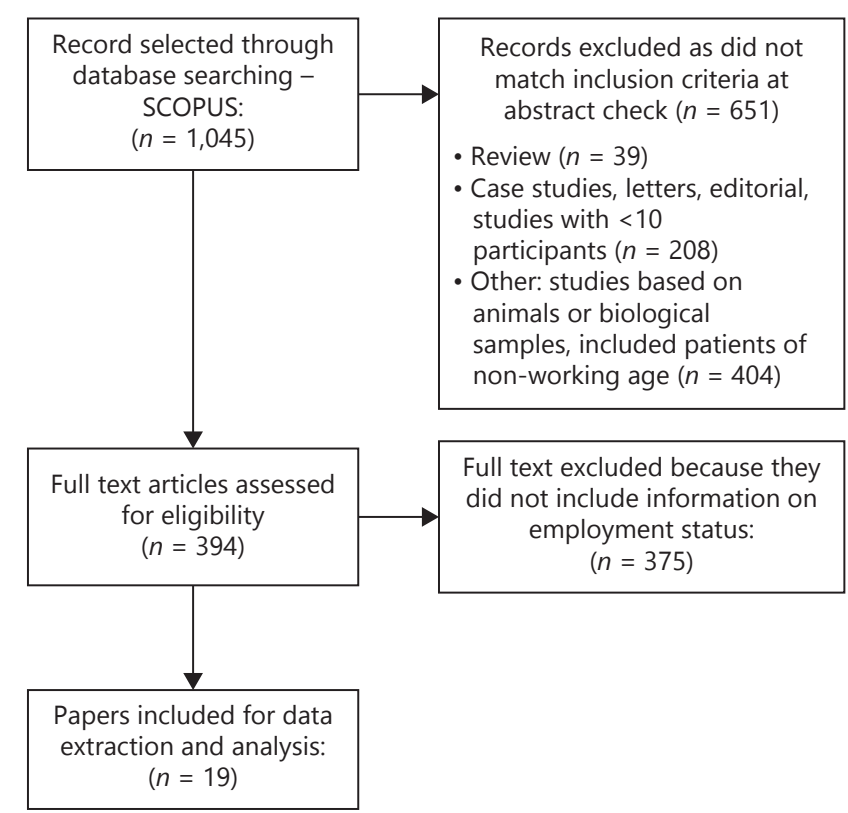

19, 27-42]. Table 1 reports the information extracted for each single study. In total, 3,600 participants were included in the different studies, of whom 2,140 were females and with an average age of 47.5 (range 35-60): of all included participants, 1,579 were employed.

Figure 2 shows the forest plot of the proportion of workers in each study: such a proportion varied from 28 [31] to $82 \%$ [19], with an extreme heterogeneity between studies. Overall, the pooled proportion of workers was 50\% (95\% CI 41-60\%).

Table 2 reports the summary statistics of the subgroup analyses. Results showed no significant differences between groups, although higher proportions were observed in studies with a percentage of women higher than $59 \%$ (+7\% compared to studies with a percentage of women lower than 59\%); with participants on average younger than 48 years ( $+15 \%$ compared to studies with participants on average older than 48 years); with $>22 \%$ of participants achieved university degree $(+14 \%$ compared to studies with a percentage of participants achieved university degree lower than $22 \%$ ); with participants with mean symptom duration lower than 8.85 years $(+17 \%$ compared to studies with participants with mean symptom duration higher than 8.85 years); with a percentage of participants thymectomized lower than $48 \%$ $(+11 \%$ compared to studies with a percentage of participants thymectomized higher than $48 \%$ ); and with a percentage of participants with generalized, bulbar, or respiratory symptoms lower than $61 \%$ of patients $(+10 \%$ com- pared to studies with a percentage of participants with generalized, bulbar, or respiratory symptoms higher than $61 \%)$.

\section{Discussion/Conclusion}

The results of our meta-analysis show that the proportion of employed people with MG was 50\% (95\% CI 41$60 \%)$. This percentage is considerably low if we take into account that the average age of MG participants involved in the included studies was around 48 years, thus in peak of working life. Our results also show that there were no significant differences in the proportion of employed patients by age, gender, education, symptoms duration, thymectomy, treatment, and muscle involvement. However, higher proportions were observed in studies with a higher percentage of women, younger participants, with a higher level of education, shorter MG duration, and less frequently thymectomized, whereas a lower proportion was observed among those with generalized, bulbar, and respiratory symptoms.

Considering the mean age of participants involved in the included studies, the impact of MG on employment is relevant. The employment rate of people with chronic disease is less than half compared with that of economically active population [43]. In 2018, the employment rate of general European population aged 20-64 was 73.2\% [44]. In a Dutch study [45] that evaluated the impact of 


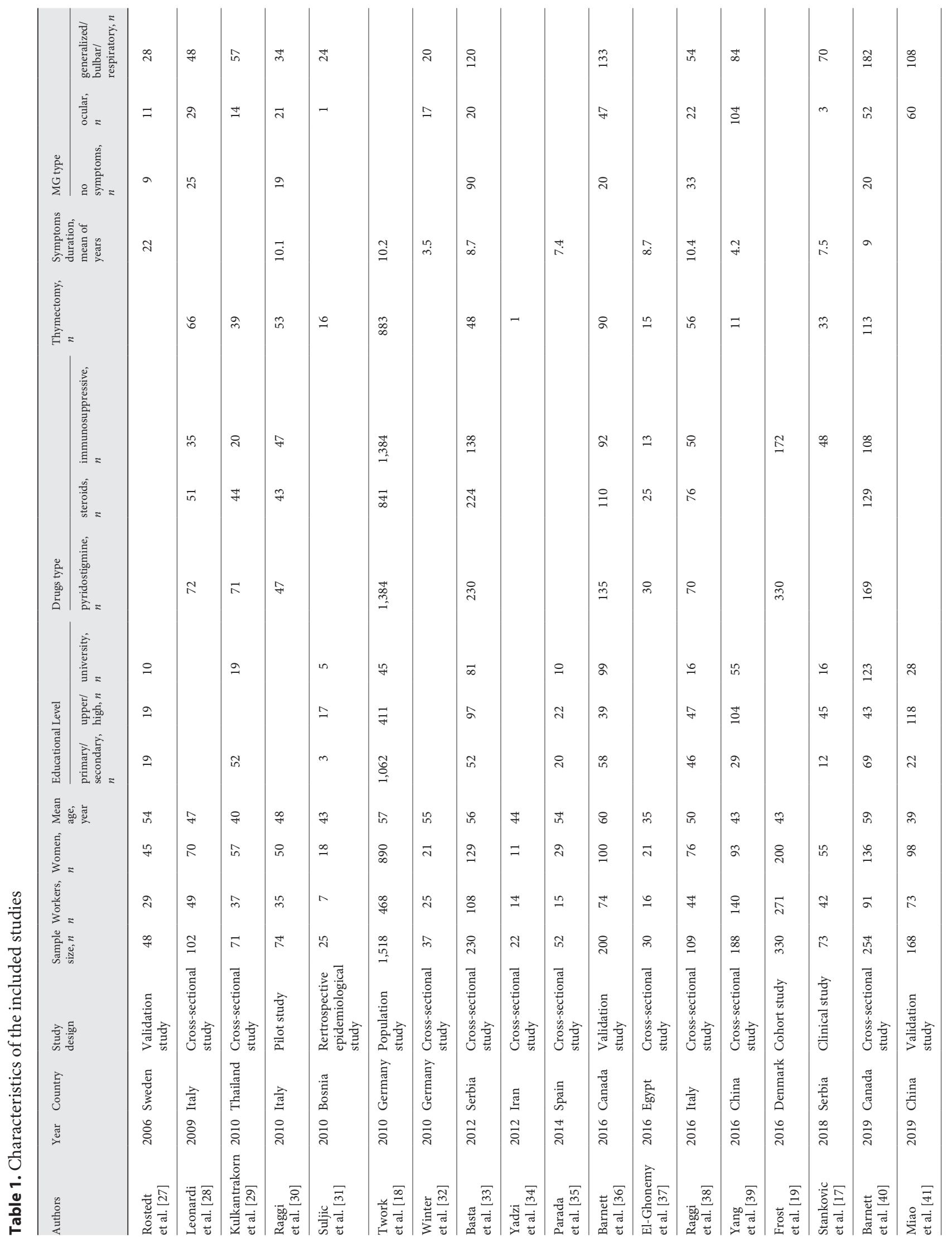




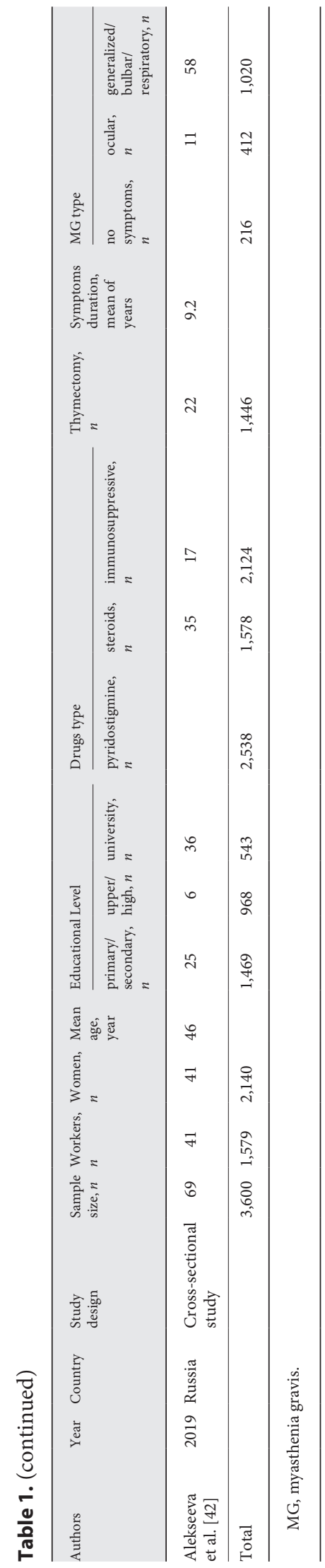

several chronic diseases on work, patients with musculoskeletal diseases had higher probabilities to have work disability and a living allowance, but they had a lower probability to be unemployed. In another study conducted on the factors related to unemployment in Europe [46], the employment rate of people with no chronic conditions was $75.5 \%$, while the employment rate of people with one or more chronic conditions was around $59 \%$. The proportion of employed patients found in our study (i.e., 50\%, 95\% CI 41-60\%) therefore show that the impact of MG on employment status is slightly stronger than the average of chronic conditions in general. If we contrast proportion of employed MG patients to the employment rates of the general population described above, that is, around $75 \%$ [44-46], we can reasonably presume that MG is responsible for a $15-35 \%$ decrease. Such an information is however to be read with caution. In fact the mean age of participants to the different studies ranged between 35 and 60 years: so it is reasonable that a portion of participants may be retired due to age.

Therefore, it is important to understand what kind of influence MG exerts on work dynamics. Although we found no significant differences in the proportion of employed MG patients by age, gender, education, symptoms duration, thymectomy, treatment, and muscle involvement, some trends can be reported. Our data in fact suggested a possible higher proportion of workers among women, younger participants, those with a higher level of education, shorter MG duration, and non-thymectomized ones, whereas a lower proportion was observed among those with generalized, bulbar, and respiratory symptoms. It has however to be carefully considered that we could rely on a limited number of studies, namely, 19 drawn out of a set of 1,045 records, that is, $<2 \%$ : these variables need therefore to be exploited in future retrospective and prospective analyses, to ascertain whether they are or not predictors of job loss. It is moreover desirable that information on employment status in MG patients is routinely reported, so that future analyses may collect relevant data also on investments on health on containment of indirect costs. Heterogeneity of results emerged here as a problem with interpretation of data, as the percentage of employed patients ranged between 28 and $82 \%$. Other reviews facing the same problem, for example, Wo et al. [47] did not perform meta-analysis and decided to report trends between variables, such as the inverse trend between clinical severity and employment rates, or differences by countries or year in which the study was carried out. In our case, choosing to highlight the heterogeneity of results by a meta-analysis was a way to focus the attention of researchers on employment in MG patients. 


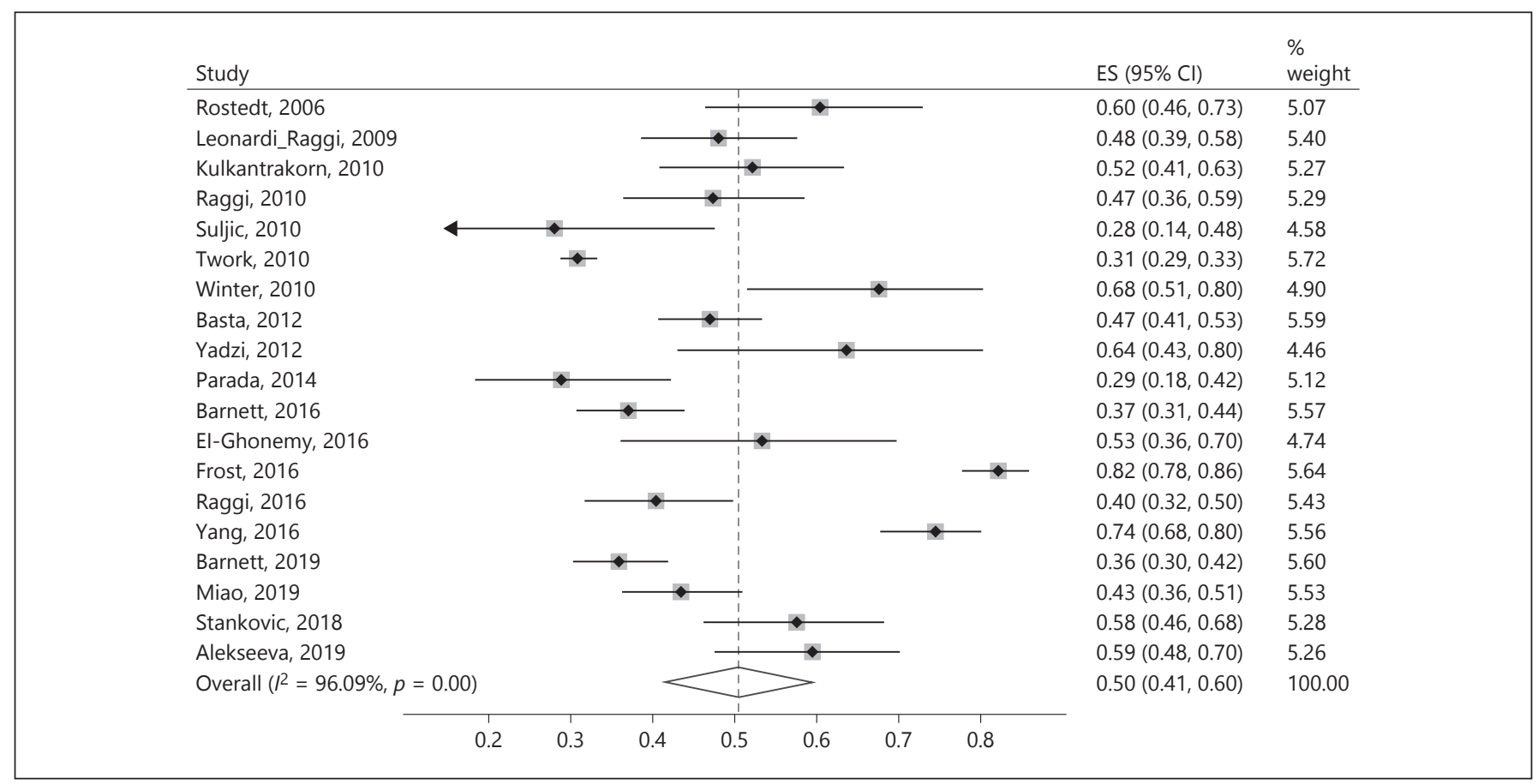

Fig. 2. Forest plot for the overall employment rate. Estimated proportion (ES) of workers.

The connection between MG and job loss deserves more attention given the obvious implication of unemployment in terms of societal costs of the disease, as well as in terms of its effect on patients' QoL. Research has shown that QoL and employment status are strictly connected variables [48-50], and QoL in MG is an outcome of importance, as treatment for MG is a lifelong one [50], and QoL in MG patients is lower than normative values [27, 51-54]. However, the majority of papers addressing QoL of MG patients did not account for employment status and even less for the way MG can affect work performance. Only Twork et al. [18] took into consideration the employment status and found that work-related capabilities of MG patients are limited by physical impairments, which is consistent with the features of MG. However, many people carry out work-related tasks that involve cognitive rather than physical skills, and in which fatigue may likewise exert some effect, but the understanding of the existence and the degree of such an association is in its infancy.

Job loss of course is a driver of increased financial burden of MG. Most of the studies, such as those by Guptill et al. $[55,56]$, addressed only direct healthcare cost related to MG. Indirect costs were addressed by a German study [57], where the total annual costs of MG were around Euro 14,950 per patient, of whom 2,790 (i.e., 19\%) was due to indirect cost, and premature retirement held the second rank among MG cost categories. In the analysis of Twork et al. [18], MG had an influence on patient's workforce participation, as $8.5 \%$ of MG patients changed their job due to MG, $21 \%$ experienced difficulties in their job and $28.3 \%$ early retired. Issues connected to employment have however to be defined also on the actual reasons for not being employed, which include, for example, age-related retirement, sick leave, maternity leave, or personal decision (e.g., being an housekeeper). Future prospective studies should address such differences.

Limitations of this study are referred, first of all, to the use of SCOPUS only for the search. Such a choice was based on its wide coverage, which would have enable to reach a wide set of document, including those of nonmedical journals. Second, we used only "myasthenia" as a search term and excluded those areas that were likely not relevant (e.g., nonhuman, child/adolescents, human tissue): we cannot be completely sure that some of these documents contained information on employment status.

In conclusion, our meta-analytic review on employment status of patients with MG, covering the period from January 2000 to May 2019, shows that the proportion of employed MG patients was 50\% (95\% CI 41-60\%). It has to be noted that the information herein produced was based on a limited number of studies, the main rea- 
Table 2. Percentage of workers in subgroups analysis

\begin{tabular}{|c|c|c|c|}
\hline Variable & Subgroups, \% & $\begin{array}{l}\text { Percentage of } \\
\text { employment } \\
(95 \% \mathrm{CI})\end{array}$ & $\begin{array}{l}\text { Heterogeneity } \\
\text { between groups } \\
p \text { value }\end{array}$ \\
\hline Gender & $\begin{array}{l}\text { Women } \geq 59 \\
\text { Women }<59\end{array}$ & $\begin{array}{l}54(0.41-0.66) \\
47(0.36-0.57)\end{array}$ & 0.413 \\
\hline Age, years & $\begin{array}{l}\geq 48 \\
<48\end{array}$ & $\begin{array}{l}42(0.36-0.49) \\
57(0.44-0.70)\end{array}$ & 0.052 \\
\hline Primary and secondary education & $\begin{array}{l}\text { Up to secondary school } \geq 29 \\
\text { Up to secondary school }<29\end{array}$ & $\begin{array}{l}43(0.34-0.52) \\
49(0.35-0.62)\end{array}$ & 0.519 \\
\hline Upper school education & $\begin{array}{l}\text { High school diploma } \geq 42 \\
\text { High school diploma }<42\end{array}$ & $\begin{array}{l}46(0.31-0.62) \\
43(0.35-0.52)\end{array}$ & 0.752 \\
\hline University & $\begin{array}{l}\text { University degree } \geq 22 \\
\text { University degree }<22\end{array}$ & $\begin{array}{l}52(0.40-0.63) \\
38(0.30-0.47)\end{array}$ & 0.075 \\
\hline Symptom duration, years & $\begin{array}{l}\text { Symptoms duration } \geq 8.85 \\
\text { Symptoms duration }<8.85\end{array}$ & $\begin{array}{l}39(0.32-0.46) \\
53(0.40-0.67)\end{array}$ & 0.057 \\
\hline Thymectomy & $\begin{array}{l}\text { Thymectomy } \geq 48 \\
\text { Thymectomy }<48\end{array}$ & $\begin{array}{l}42(0.34-0.52) \\
53(0.41-0.65)\end{array}$ & 0.179 \\
\hline Pyridostigmine drugs & $\begin{array}{l}\text { Pyridostigmine drugs } \geq 81 \\
\text { Pyridostigmine drugs }<81\end{array}$ & $\begin{array}{l}53(0.29-0.77) \\
40(0.36-0.45)\end{array}$ & 0.315 \\
\hline Steroids drugs & $\begin{array}{l}\text { Steroid drugs } \geq 57 \\
\text { Steroid drugs }<57\end{array}$ & $\begin{array}{l}47(0.42-0.51) \\
41(0.33-0.49)\end{array}$ & 0.218 \\
\hline Immunosuppressive drugs & $\begin{array}{l}\text { Immunosuppressive drugs } \geq 46 \\
\text { Immunosuppressive drugs }<46\end{array}$ & $\begin{array}{l}51(0.31-0.71) \\
46(0.38-0.54)\end{array}$ & 0.659 \\
\hline No symptoms & $\begin{array}{l}\text { No symptoms } \geq 25 \\
\text { No symptoms }<25\end{array}$ & $\begin{array}{l}46(0.41-0.50) \\
42(0.32-0.53)\end{array}$ & 0.552 \\
\hline Ocular symptoms & $\begin{array}{l}\text { Ocular symptoms } \geq 22 \\
\text { Ocular symptoms }<22\end{array}$ & $\begin{array}{l}54(0.42-0.66) \\
46(0.39-0.54)\end{array}$ & 0.295 \\
\hline $\begin{array}{l}\text { Generalized, bulbar, or } \\
\text { respiratory symptoms }\end{array}$ & $\begin{array}{l}\text { Generalized, bulbar, or } \\
\text { respiratory symptoms } \geq 61 \\
\text { Generalized, bulbar, or } \\
\text { respiratory symptoms }<61\end{array}$ & $\begin{array}{l}45(0.37-0.52) \\
55(0.44-0.66)\end{array}$ & 0.139 \\
\hline
\end{tabular}

son being the overall lack of data on employment status in the vast majority of the studies retrieved by our search. If contrasted to data on the general populations, for whom employment rates were reported around $75 \%$, we can presume that MG is responsible for a $15-35 \%$ decrease in the proportion of employed subjects.

As a chronic disease, MG has a severe impact on patients' lives and their socioeconomic status. The loss of productivity, premature retirement, or job loss can cause relevant problems both on outcomes of the diseases and on QoL. Future studies should explore the effect of MG on employment status, either retrospectively and pro- spectively, and the information on employment status of MG patients should routinely be reported: in this way, future meta-analytic reviews might collect more data and give more consistent results on the effect of investments on health over indirect cost reduction.

\section{Acknowledgment}

A.R. is supported by a grant from the Italian Ministry of Health (Ricerca Corrente, Fondazione Istituto Neurologico C. Besta, Linea 4 - Outcome Research: dagli Indicatori alle Raccomandazioni Cliniche). 


\section{Statement of Ethics}

Not applicable.

\section{Disclosure Statement}

The authors have no conflicts of interest to declare.

\section{Funding Sources}

No funding was available for this manuscript.

\section{Author Contributions}

E.G. conception, literature review phase, writing of the first draft, review, and critique. I.T. analysis, review, and critique. C.T. literature review phase, review, and critique. M.L. and R.M. conception, review, and critique. S.B. and R.F. review and critique. A.R. conception, literature review phase, review, and critique.

\section{References}

1 Querol L, Illa I. Myasthenia gravis and the neuromuscular junction. Curr Opin Neurol. 2013 Oct;26(5):459-65.

2 Gilhus NE, Verschuuren JJ. Myasthenia gravis: subgroup classification and therapeutic strategies. Lancet Neurol. 2015 Oct;14(10):1023-36.

3 Mantegazza R, Baggi F, Antozzi C, Confalonieri P, Morandi L, Bernasconi P, et al. Myasthenia gravis (MG): epidemiological data and prognostic factors. Ann N Y Acad Sci. 2003 Sep;998(1):413-23.

4 Gilhus NE, Skeie GO, Romi F, Lazaridis K, Zisimopoulou P, Tzartos S. Myasthenia gravis - autoantibody characteristics and their implications for therapy. Nat Rev Neurol. 2016 May;12(5):259-68.

5 Cetin H, Fülöp G, Zach H, Auff E, Zimprich F. Epidemiology of myasthenia gravis in Austria: rising prevalence in an ageing society. Wien Klin Wochenschr. 2012 Nov; 124(2122):763-8.

6 Park SY, Lee JY, Lim NG, Hong YH. Incidence and Prevalence of Myashtenia Gravis in Korea: A Population-Based Study Using the National Health Insurance Claims Database. J Clin Neurol. 2016 Jul;12(3):340-4.

7 Aragonès JM, Altimiras J, Roura P, Alonso F, Bufill E, Munmany A, et al. Prevalence of myasthenia gravis in the Catalan county of Osona. Neurologia. 2017 Jan - Feb;32(1):1-5.

8 Vincent A, Palace J, Hilton-Jones D. Myasthenia gravis. Lancet. 2001 Jun;357(9274): 2122-8.

9 Conti-Fine BM, Milani M, Kaminski HJ. Myasthenia gravis: past, present, and future. J Clin Invest. 2006 Nov;116(11):2843-54.

10 Cioncoloni D, Casali S, Ginanneschi F, Carone M, Veronica B, Rossi A, et al. Major motor-functional determinants associated with poor self-reported health-related quality of life in myasthenia gravis patients. Neurol Sci. 2016 May;37(5):717-23.

11 Raggi A, Antozzi C, Baggi F, Leonardi M, Maggi L, Mantegazza R. Validity, reliability, and sensitivity to change of the myasthenia gravis activities of daily living profile in a sample of Italian myasthenic patients. Neurol Sci. 2017 Nov;38(11):1927-31.
12 Paul RH, Nash JM, Cohen RA, Gilchrist JM, Goldstein JM. Quality of life and well-being of patients with myasthenia gravis. Muscle Nerve. 2001 Apr;24(4):512-6.

13 Sieminski M, Bilińska M, Nyka WM. Increased frequency of restless legs syndrome in myasthenia gravis. Eur Neurol. 2012;68(3):166-70.

14 Cejvanovic S, Vissing J. Muscle strength in myasthenia gravis. Acta Neurol Scand. 2014 Jun;129(6):367-73.

15 Alekseeva TM, Gavrilov YV, Kreis OA, Valko PO, Weber KP, Valko Y. Fatigue in patients with myasthenia gravis. J Neurol. 2018 Oct; 265(10):2312-21.

16 Kotan VO, Kotan Z, Aydin B. Psychopatology, Psychosocial Factors and Quality of Life in Patients with Myasthenia Gravis. J Neurol Sci. 2016;33:482-93.

17 Stankovic M, Peric S, Stojilikovic Tamas O, Stankovic T, Nikolic A, Lavrnic D, et al. Quality of life in patients with MuSK positive myasthenia gravis. Acta Neurol Belg. 2018 Sep; 118(3):423-7.

18 Twork S, Wiesmeth S, Klewer J, Pohlau D, Kugler J. Quality of life and life circumstances in German myasthenia gravis patients. Health Qual Life Outcomes. 2010 Nov;8:129.

19 Frost A, Svendsen ML, Rahbek J, Stapelfeldt CM, Nielsen CV, Lund T. Labour market participation and sick leave among patients diagnosed with myasthenia gravis in Denmark 1997-2011: a Danish nationwide cohort study. BMC Neurol. 2016 Nov;16(1):224.

20 Jaretzki A 3rd, Barohn RJ, Ernstoff RM, Kaminski HJ, Keesey JC, Penn AS, et al.; Task Force of the Medical Scientific Advisory Board of the Myasthenia Gravis Foundation of America. Myasthenia gravis: recommendations for clinical research standards. Neurology. 2000 Jul;55(1):16-23.

21 Antozzi C, Brenna G, Baggi F, Camera G, Maggi L, Rezzani C, et al. Validation of the Besta Neurological Institute rating scale for myasthenia gravis. Muscle Nerve. 2016 Jan;53(1):32-7.

22 Newcombe RG. Two-sided confidence intervals for the single proportion: comparison of seven methods. Stat Med. 1998 Apr;17(8): 857-72.
23 DerSimonian R, Laird N. Meta-analysis in clinical trials. Control Clin Trials. 1986 Sep; 7(3):177-88.

24 Freeman MF, Tukey JW. Transformations related to the angular and the square root. Ann Math Stat. 1950;21(4):607-11.

25 Greenland S. Quantitative methods in the review of epidemiologic literature. Epidemiol Rev. 1987;9(1):1-30.

26 Higgins JP, Thompson SG, Deeks JJ, Altman DG. Measuring inconsistency in meta-analyses. BMJ. 2003 Sep;327(7414):557-60.

27 Rostedt A, Padua L, Stålberg EV. Validation of the Swedish version of the disease-specific Myasthenia Gravis Questionnaire. Neurol Sci. 2006 Jun;27(2):91-6.

28 Leonardi M, Raggi A, Antozzi C, Confalonieri P, Maggi L, Cornelio F, et al. Identification of international classification of functioning, disability and health relevant categories to describe functioning and disability of patients with myasthenia gravis. Disabil Rehabil. 2009; 31(24):2041-6.

29 Kulkantrakorn K, Sawanyawisuth K, Tiamkao $S$. Factors correlating quality of life in patients with myasthenia gravis. Neurol Sci. 2010 Oct;31(5):571-3.

30 Raggi A, Leonardi M, Mantegazza R, Casale S, Fioravanti G. Social support and self-efficacy in patients with Myasthenia Gravis: a common pathway towards positive health outcomes. Neurol Sci. 2010 Apr;31(2):231-5.

31 Suljic E, Kavazovic A, Loncarevic N. How the application of human immunoglobulin in the treatment of myasthenia crisis changed the outcome of the disease. Med Arh. 2010;64(1): 7-10.

32 Winter Y, Schepelmann K, Spottke AE, Claus D, Grothe C, Schröder R, et al. Health-related quality of life in ALS, myasthenia gravis and facioscapulohumeral muscular dystrophy. J Neurol. 2010 Sep;257(9):1473-81.

33 Basta IZ, Pekmezović TD, Perić SZ, KisićTepavčević DB, Rakočević-Stojanović VM, Stević ZD, et al. Assessment of health-related quality of life in patients with myasthenia gravis in Belgrade (Serbia). Neurol Sci. 2012 Dec; 33(6):1375-81. 
34 Yazdi MF, Baghianimoghadam M, Nazmiyeh $\mathrm{H}$, Ahmadabadi AD, Adabi MA. Response to plasmapheresis in myasthenia gravis patients: 22 cases report. Rom J Intern Med. 2012 JulSep;50(3):245-7.

35 Parada P, Oliva M, Lázaro E. Anxiety, Depression and Self-Efficacy in Patients with Myasthenia Gravis. IJP\&PT. 2014;14:105-13.

36 Barnett C, Bril V, Kapral M, Kulkarni A, Davis AM. Development and validation of the Myasthenia Gravis Impairment Index. Neurology. 2016 Aug;87(9):879-86.

37 El-Ghonemy SH, Salem HH, El-Missiry M, El-Ghamry RH, Mukhtar YS. Myasthenia gravis and psychiatric comorbidities. Middle East Current Psychiatry. 2016;23(2):99-105.

38 Raggi A, Leonardi M, Schiavolin S, Antozzi C, Brenna G, Maggi L, et al. Validation of the MG-DIS: a disability assessment for myasthenia gravis. J Neurol. 2016 May;263(5):871-82.

39 Yang Y, Zhang M, Guo J, Ma S, Fan L, Wang $\mathrm{X}$, et al. Quality of life in 188 patients with myasthenia gravis in China. Int J Neurosci. 2016;126(5):455-62.

40 Barnett C, Bril V, Bayoumi AM. EQ-5D-5L and SF-6D health utility index scores in patients with myasthenia gravis. Eur J Neurol. 2019 Mar;26(3):452-9.

41 Miao X, Lian Z, Liu J, Chen H, Shi Z, Li M, et al. Translation, cross-cultural adaptation, and validation of the chinese version of the 15 item myasthenia gravis quality of life questionnaire. Muscle Nerve. 2019 Jan;59(1):95-9.

42 Alekseeva TM, Kreis OA, Gavrilov YV, Valko PO, Weber KP, Valko Y. Impact of autoimmune comorbidity on fatigue, sleepiness and mood in myasthenia gravis. J Neurol. 2019 Aug;266(8):2027-34.

43 European Commission. European Disability Strategy 2010-2020: A Renewed Commit- ment to a Barrier-Free Europe. EU: Brussels, Belgium, 2010. [Accessed October 8, 2019]. Available from: https://eur-lex.europa.eu/ LexUriServ/LexUriServ.do?uri=COM: 2010: 0636:FIN:en:PDF.

44 EUROSTAT. 2019. Employment rate and Europe 2020 National targets. [Accessed October $8,2019]$. Available from: https://ec.europa.eu/ eurostat/statistics-explained/index.php/Employment_rates_and_Europe_2020_national_targets\#Persistent_increase_of_the_employment_rate_at_EU_level.

45 van der Zee-Neuen A, Putrik P, Ramiro S, Keszei A, de Bie R, Chorus A, et al. Work outcome in persons with musculoskeletal diseases: comparison with other chronic diseases \& the role of musculoskeletal diseases in multimorbidity. BMC Musculoskelet Disord. 2017 Jan;18(1):10.

46 Leonardi M, Guido D, Quintas R, Silvaggi F, Guastafierro E, Martinuzzi A, et al. Factors Related to Unemployment in Europe. A Cross-Sectional Study from the COURAGE Survey in Finland, Poland and Spain. Int J Environ Res Public Health. 2018 Apr;15(4):722.

47 Wo MC, Lim KS, Choo WY, Tan CT. Employability in people with epilepsy: A systematic review. Epilepsy Res. 2015 Oct;116:67-78.

48 Kim J, Noh JW, Park J, Huh T, Kwon YD. Association between health-related quality of life and work status in older Korean adults. Geriatr Gerontol Int. 2018 Dec;18(12):1629-33.

49 Min D, Cho E. Patterns in quality of life according to employment among the older adults: the Korean longitudinal study of aging (2008-2014). BMC Public Health. 2018 Mar; 18(1):379

50 Merchant JA, Kelly KM, Burmeister LF, Lozier MJ, Amendola A, Lind DP, et al. Employment status matters: a statewide survey of quality-of-life, prevention behaviors, and absenteeism and presenteeism. J Occup Environ Med. 2014 Jul;56(7):686-98.

51 Boldingh MI, Dekker L, Maniaol AH, Brunborg C, Lipka AF, Niks EH, et al. An up-date on health-related quality of life in myasthenia gravis -results from population based cohorts. Health Qual Life Outcomes. 2015 Aug;13(1): 115

52 Padua L, Evoli A, Aprile I, Caliandro P, Mazza S, Padua R, et al. Health-related quality of life in patients with myasthenia gravis and the relationship between patient-oriented assessment and conventional measurements. Neurol Sci. 2001 Oct;22(5):363-9.

53 Raggi A, Leonardi M, Antozzi C, Confalonieri P, Maggi L, Cornelio F, et al. Concordance between severity of disease, disability and health-related quality of life in myasthenia gravis. Neurol Sci. 2010 Feb;31(1):41-5.

54 Leonardi M, Raggi A, Antozzi C, Confalonieri $\mathrm{P}$, Maggi L, Cornelio F, et al. The relationship between health, disability and quality of life in myasthenia gravis: results from an Italian study. J Neurol. 2010 Jan;257(1):98-102.

55 Guptill JT, Marano A, Krueger A, Sanders DB. Cost analysis of myasthenia gravis from a large U.S. insurance database. Muscle Nerve. 2011 Dec;44(6):907-11.

56 Guptill JT, Sharma BK, Marano A, Soucy A, Krueger A, Sanders DB. Estimated cost of treating myasthenia gravis in an insured U.S. population. Muscle Nerve. 2012 Mar;45(3): 363-6.

57 Schepelmann K, Winter Y, Spottke AE, Claus $\mathrm{D}$, Grothe C, Schröder R, et al. Socioeconomic burden of amyotrophic lateral sclerosis, myasthenia gravis and facioscapulohumeral muscular dystrophy. J Neurol. 2010 Jan;257(1): 15-23. 